\title{
ОСНОВНЫЕ ЗАДАЧИ И ПУТИ УПРАВЛЕНИЯ ОТРАСЛЕВЫМИ РИСКАМИ *
}

\author{
(c) 2020 Мельникова Л.А.
}

кандидат экономических наук, доцент Департамента бизнес-аналитики

Финансовый университет при Правительстве Российской Федерации, Россия, Москва

E-mail: lamelnikova@mail.ru

(c) 2020 Гордова М. А.

кандидат экономических наук,

старший преподаватель Департамента аудита и корпоративной отчетности

Финансовый университет при Правительстве Российской Федерации, Россия, Москва

E-mail: MGordova@fa.ru

(c) 2020 Попова С.C.

кандидат экономических наук, менеджер Департамента бизнес-аналитики

Финансовый университет при Правительстве Российской Федерации, Россия, Москва

E-mail: SSPopova@fa.ru

Основной задачей управления рисками в настоящих условиях хозяйствования выступает задача их минимизации. Минимизация отраслевых рисков возможна при разработке эффективной системы оценки ключевых индикаторов риска, которые направлены на выявление соответствующих показателей, предоставляющих необходимую информацию о потенциальных рисках, оказывающих влияние на достижение стратегических целей экономического субъекта. Разработка эффективной системы ключевых индикаторов риска начинается с анализа и оценки влияния рисков, как на достижение целей экономических субъектов, так и конкурентной среды. Взаимосвязь ключевых показателей риска позволяет выявить наиболее актуальную информацию, служащую в качестве индикатора, сигнализирующего о возникновении существенного риска.

Процесс выработки эффективной системы ключевых индикаторов риска начинается с анализа угрожающего события, негативно влияющего на субъект хозяйствования. Без внимания не должны оставаться промежуточные и первичные события, предшествующие наступлению негативной ситуации, которая влечет за собой существенный ущерб или приводит к упущению экономической выгоды. Основной задачей процесса формирования необходимых индикаторов обуславливается выработка показателей, предоставляющих объективную информацию о возможности осуществления угрожающего события. Чем ближе индикатор к источнику угрозы, тем выше вероятность того, что менеджмент субъекта хозяйствования предпримет необходимые действия, нивелирующие риск, для предотвращения наступления опасного события.

Неоспоримым фактором является то, что основной стратегической целью деятельности субъекта хозяйствования является получение прибыли. Получение прибыли обеспечивает бесперебойная работа всех бизнес процессов, а именно: процесса обеспечения ресурсами производственного процесса, ритмичность производственного процесса, эффективная ценовая и маркетинговая политика, привлечение инвестиций для развития субъекта хозяйствования и т.д. Нарушение отлаженности всех обусловленных процессов указывает на возникновение угроз как внутреннего, так и внешнего характера, ставящих под угрозу выполнение вышеописанных стратегических задач деятельности и функционирования экономического субъекта в целом.

Объектом исследования выступят угрозы и риски, сопровождающие финансово-хозяйственную деятельность экономических субъектов. Предмет исследования определяется систематизацией задач и путей управления отраслевыми рисками.

Ключевые слова: деятельность, задачи, инвестиции, исследование, обеспечение, оценка угроз, процесс, пути управления, ресурсы, ритмичность, экономическая выгода.

\footnotetext{
* Статья подготовлена по результатам исследований, выполненных за счет бюджетных средств по государственному заданию Финуниверситету.
} 
Хозяйствующие субъекты осуществляют свою деятельность для увеличения доходности в будущем, в соответствии с чем, можно выделить основные задачи субъекта хозяйствования на сегодняшний день: стабильное обеспечение потребителей продукцией, выпускаемой экономическим субъектом, в соответствии с заключенными контрактами и рыночным спросом; недопущение сбоев в производственном процессе экономического субъекта; обеспечение персонала заработной платой и привлекательными условиями труда, а также возможностью профессионального роста; охрана экологии окружающей среды. Финансово-хозяйственная деятельность в свою очередь подвержена влиянию внешней и внутренней среды, а также сопряженными с их влиянием угрозами и рисками.

Вопросами управления рисками и предшествующими им угрозами занимаются российские специалисты, из которых следует отметить научные работы: О.И. Васильчук, В.В.Шнайдер $[1$, 5, 6]， Л.В.Глуховой， Б.В.Казиевой， К.В.Казиева, В.М.Казиева, А.А.Шерстобитовой [2], Н. О. Михалёнок [3], А. С.Шапкина, В.А.Шапкина [4], А.М.Петрова, М.В.Боровицкой, О.В.Шнайдер [7].

Задачами системы управления отраслевыми рисками являются: выявление, сбор, обработка и хранение информации о внутренней и внешней среде; формирование системы факторов риска для экономического субъекта; определение угроз, выявленных факторами риска; выработка стратегии; разработка программы мероприятий по снижению уровня вероятности наступления угроз и иных инвестиционно-проектных мероприятий; ведения учета и отчетности по рисковым решениям.

Основные этапы управления рисками иллюстрированы на рисунке 1 .

Анализ полученных в ходе проведения оценки риска данных способствует принятию решений о целесообразности проведения мероприятий по снижению риска (рисунок 2). К таким мероприятиям можно отнести:

- нивелирование риска (консервация деятельности, вызывающей риск);

- снижение риска; принятие риска на себя;

- разделение риска с контрагентами (контракты, финансирование).

Если инвестор принимает решение о сохранении риска, это означает, что он оставляет риск за собой и рассчитывает покрыть возможные потери собственными средствами. Сохранение риска возможно с помощью его локализации, если через выделение отдельных организационноправовых форм выявить источник риска не удается.

Косвенные индикаторы определяют изменение уровня риска с помощью отслеживания фактов и ключевых событий, которые косвенно свидетельствуют о возможности реализации нежелательного события. Такие индикаторы включают ошибки и погрешности. Причинноследственные индикаторы - это показатели, не-

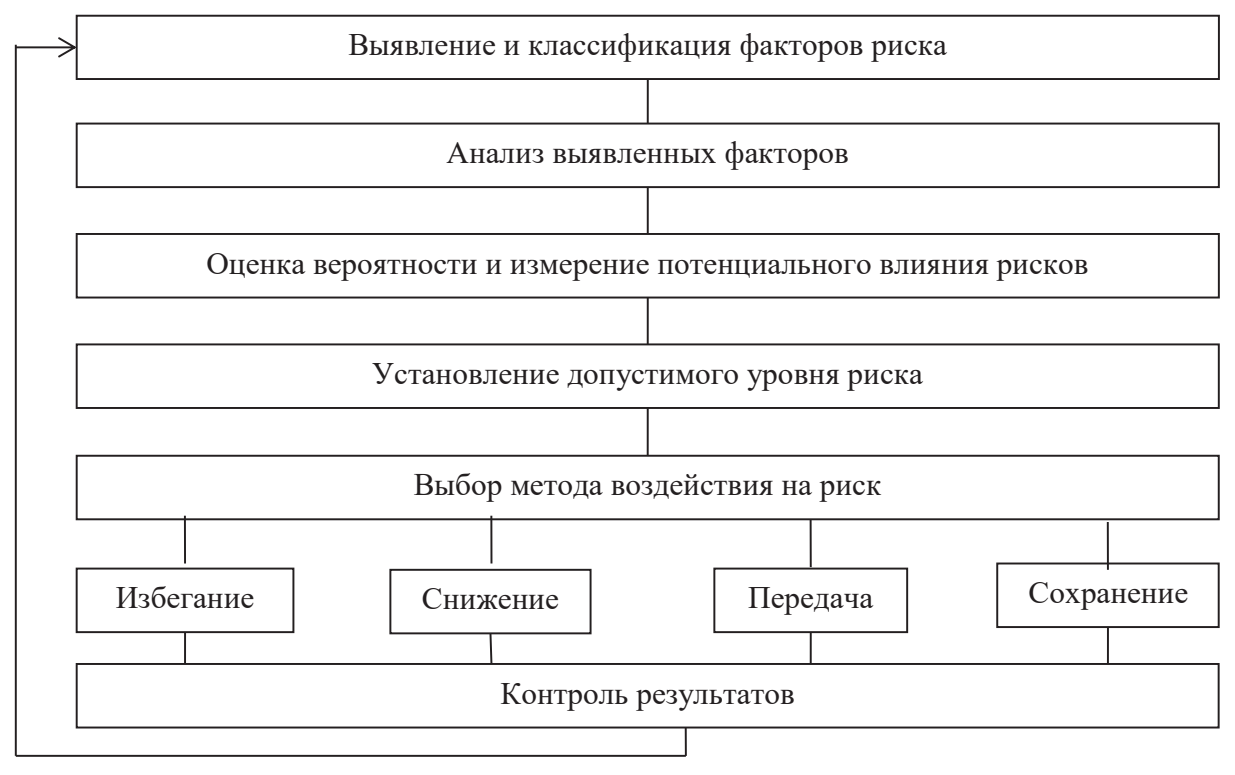

Рисунок 1. Схема управления рисками

Источник: составлено авторами на основе научной статьи [4] 


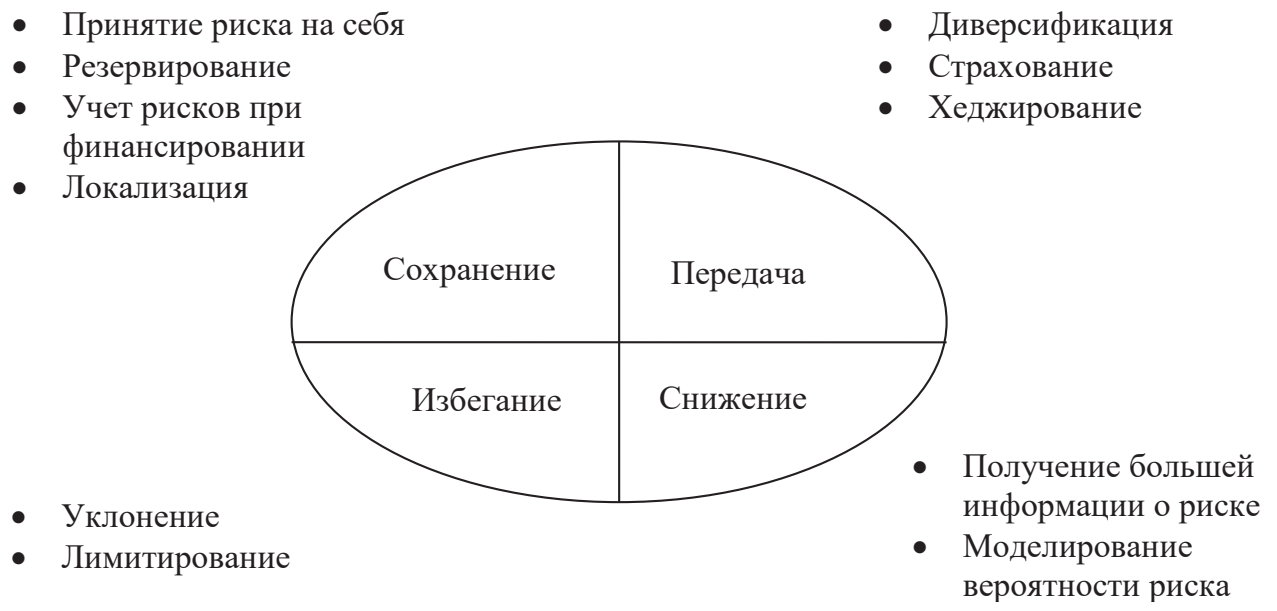

Рисунок 2. Методы управления рисками Источник: составлено авторами.

посредственно связанные с источниками нежелательных событий. Контрольные индикаторы эффективности используются для текущего мониторинга исполнения регламента или контроля за соблюдением установленных нормативов. Индикаторы объема (неотъемлемые показатели риска) являются ключевыми показателями эффективности. Данные показатели позволяют отслеживать изменение определенных показателей или влиять на повышение вероятности нежелательного события, например, на величину убытков от мошеннических действий. Индикаторы объема неразрывно связаны с несколькими видами риска в процессе деятельности одного субъекта хозяйствования.

Связь стратегических задач с риском и ключевыми индикаторами риска проиллюстрирована на рисунке 3.

В соответствии с данными рисунка 3, ключевые идентификаторы определяются для каждого угрожающего риска. Сопоставление ключевых идентификаторов с угрожающим риском по- зволяют менеджменту субъекта хозяйствования меньше отвлекаться на прочие сведения, являющиеся актуальными для достижения целей субъекта хозяйствования, и расставить правильные приоритеты.

Процесс выработки эффективной системы ключевых индикаторов риска отражен на рисунке 4.

На рисунке 4 проиллюстрирован процесс, в котором выделяется причинно-следственная связь между событием, которое произошло, и причиной возникновения данного события. Разработка индикаторов помогает отследить всю цепь событий, которые приводят к угрозе, и предпринимать действия, нацеленные на нивелирование воздействия риска каждого этапа развития нежелательного события, которое угрожает возможности выполнения цели. Если менеджмент экономического субъекта имеет достаточное количество информации для определения ключевой причины, способной повлиять на возникновение нежелательного события,

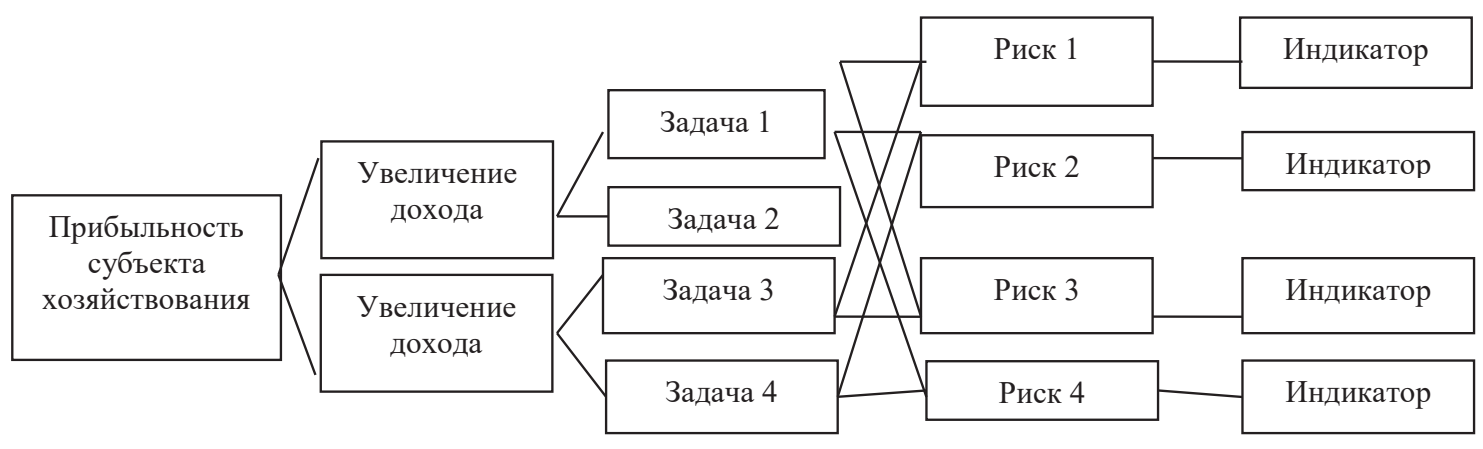

Рисунок 3. Иллюстрация системы ключевых индикаторов риска субъекта хозяйствования Источник: составлено авторами. 


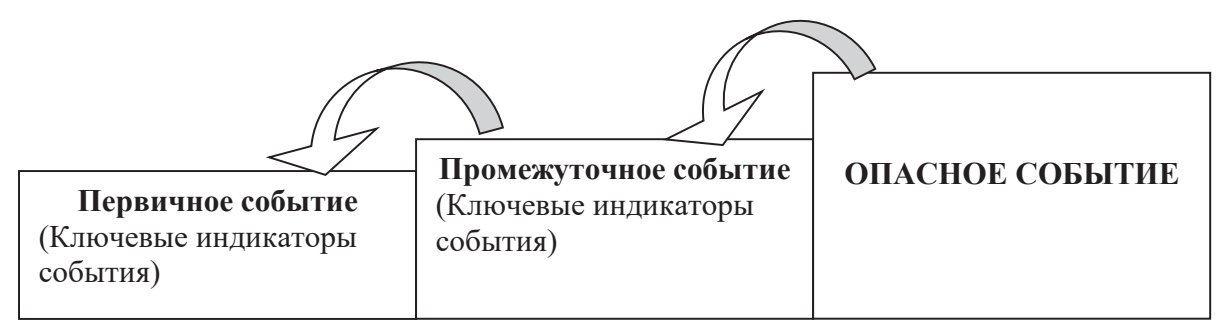

Рисунок 4. Процесс отбора ключевых индикаторов риска Источник: составлено авторами.

можно сделать вывод, что в таком случае менеджмент обладает рычагами воздействия на предотвращение негативных последствий.

В заключении отметим, что приоритезация индикаторов риска может помочь пользователям информации уделять внимание наиболее значимым индикаторам для субъекта хозяйствования. Определение приоритетов можно автоматизировать через использование предельных уровней, но в этом случае требуется оперативное решение ответственного лица за оценку риска. Экономическим субъектам также следует рассмотреть вопрос о согласовании не- которых общих критериев для определения степени приоритетности индикаторов риска, учитывая при этом, что уровень приоритетности может быть различным в зависимости от уровня, на котором индикаторы рассматриваются в рамках субъекта хозяйствования. Например, в крупных экономических субъектах уровень значимости может быть выше на общем уровне, в связи с этим, на разных уровнях управления, возможно, потребуется согласовать различные критерии для определения приоритетности тех или иных индикаторов и связанных с ними рисков.

\section{Библиографический список}

1. Васильчук О.И., Шнайдер В.В. Ключевые аспекты современного антикризисного консалтинга // Гуманитарные балканские исследования. 2019. Т. 3. № 3 (5). С. 105-107.

2. Глухова Л.В., Казиева Б. В., Казиев К. В., Казиев В. М., Шерстобитова А. А. Управление деятельностью инновационных систем в условиях неопределенности и риска // Вестник Волжского университета им. В.Н. Татищева. 2020. Т. 2. № 3 (46). С. 50-59.

3. Михалёнок Н.О., Шнайдер В.В. Анализ финансового состояния экономических субъектов: сущность, значение и основные подходы // Вестник СамГУПС. 2018. № 3 (41). С. 84-87.

4. Шапкин А.С., Шапкин В.А. Теория риска и моделирование рисковых ситуаций: Учебник.- М.: Дашков и Кํㅜ 2006. C. 77.

5. Шнайдер В.В. Актуальные проблемы организации интегрированной подсистемы риск-менеджмента в системе финансового контроллинга // Вестник НГИЭИ. 2016. № 5 (60). С. 83-90.

6. Шнайдер В.В. Рыночная экономика, предпринимательство и мошенничество в сфере предпринимательства // Вестник СамГУПС. 2017. № 1 (35). С. 71-75.

7. Шнайдер О.В., Петров А.М., Боровицкая М.В. Система оценки рисков, обусловленных влиянием суровых климатических условий на экономику арктической зоны Российской Федерации // Экономические науки. 2019. № 171. С. $134-138$. 